\section{Novelty as a Parameter for Using Arguments in Persuasive Communication}

\section{GERJO KOK $\mathbb{D}$}

*Author affiliations can be found in the back matter of this article
EMPIRICAL PAPER

\section{] $\mathrm{u}$ [ubiquity press}

CORRESPONDING AUTHOR:

\section{Gerjo Kok}

Maastricht University, NL

g.kok@maastrichtuniversity.nl

\section{KEYWORDS:}

persuasive communication; arguments; parameters; attitude change

TO CITE THIS ARTICLE: Kok, G. (2021). Novelty as a Parameter for Using Arguments in Persuasive Communication. Health Psychology Bulletin, 5(1), pp. 12-19. DOI: https://doi. org/10.5334/hpb.13

There is a need for more experimental studies identifying parameters for effectiveness in relation to various behavior change methods. 


\section{INTRODUCTION}

Many meta-analyses addressing the effectiveness of behavior change methods have failed to take into account one or more of the four conditions that must be met for a method to effectively influence behavior (1) a method can only influence behavior if it targets beliefs that underlie a determinant that the method can change;

(2) these beliefs (and the overarching determinant) must in fact be relevant predictors of the behavior; (3) the method must be translated into a practical application that fits with the target population, its culture, and the relevant context; and (4) the parameters for effectiveness (the conditions under which the methods are shown to be effective) must be satisfied in the final application of the method (Peters et al., 2015; De Bruin et al., 2015). This last condition in particular is often not taken into account. For the coding of behavior change methods, as well as the translation of these methods into practical applications, it is not enough to simply provide a consensus-based definition. It is also essential to identify and satisfy parameters for effectiveness in relation to each chosen method (Bartholomew Eldredge et al., 2016; Kok et al., 2016; Peters \& Kok, 2016). All behavior change methods have such parameters for effectiveness (Crutzen \& Peters, 2017).

Social psychologists contribute to our knowledge about these parameters by studying behavior change in laboratory settings and conducting experiments that systematically manipulate the relevant concepts being studied. In this paper, a study investigating the parameters for effectiveness in relation to using arguments in persuasive communication messages is described. This study was part of the author's PhD dissertation (written in Dutch), and laid the groundwork for a larger study comparing the influence of arguments versus social comparison (Kok, 1983). This larger study has been published (Kok et al., 1986, in Dutch). The study described here has never been published before (unfortunately, the original data are lost and some information is not reported here because it was not reported in the dissertation or in the chapter). Nevertheless, in hindsight, the study demonstrates perfectly the relevance of parameters for effectiveness. The data are from 1983, but the process outlined here is just as relevant today.

Health promotors often use messages designed to change attitudes as a first step towards changing intentions and behaviors. One of the most widely used behavior change methods for bringing about attitude change is persuasive communication (McGuire, 2012). Persuasive communication can be defined as communication that guides individuals and environmental agents toward the adoption of an idea, attitude, or action by using arguments or other means (Petty et al., 2009). Arguments can be defined as the use of a set of one or more meaningful premises and a conclusion (Burnstein \& Vinokur, 1977; Vinokur \& Burnstein, 1978). The Elaboration Likelihood Model (Petty \& Wegener, 1998; Petty et al., 2019) predicts that high-quality arguments will be effective only when the receivers process the message through the central route, not when they use the peripheral route. A higher number of arguments does not ensure quality and, in fact, may negatively affect attitude change; they may be convincing for people who process the information through the peripheral route, but they will be less convincing for people who process through the central route. Health promotors try to develop high quality messages and ensure that those receiving these messages process them through the central route, in order to create maintenance of change.

It has been suggested (Vinokur \& Burnstein 1978; Burnstein \& Vinokur, 1977) that the following four characteristics determine the quality of arguments, that is, their effectiveness after careful processing:

Direction, the extent to which the argument supports a specific opinion $X$ or supports the opposite opinion Y;

Relevance, the extent to which the argument is relevant to the topic of the message; Validity, the extent to which the argument is true, valid and plausible;

Novelty, the extent to which the message contains new arguments, unlikely to have already been considered by the receiver.

These characteristics can be seen as parameters for effectiveness for the behavior change method 'Arguments'. Arguments are often used in persuasive communication with the aim of changing attitudes. The series of studies presented here focus on the essential - but often ignored - role of novelty: "For central processing of arguments they need to be new to the message receiver" (Bartholomew Eldredge et al., 2016, p. 385 and Kok et al., 2016, suppl. p. 10). As a consequence, health promotors try to develop high quality messages containing arguments that are new, as well as relevant and valid, and which promote change in the right direction. This combination is essential; it is easy to come up with new arguments, but is extremely difficult to provide new arguments for the target population that are also relevant, valid and in the right direction.

The question that springs to mind, then, is: How does the health promotor identify and select arguments that are new as well as relevant, valid, and also promote change in the right direction? It is not difficult to come up with new arguments; the challenge is to find new arguments that also meet the other three criteria. In the following section, we will describe three studies that, together, nicely demonstrate this process. The first study 
involves the elicitation of arguments, the second study entails the identification of new arguments, and the third study focuses on the influence of new and familiar arguments. The main hypothesis for this series of studies was: Messages with new, valid and relevant arguments will lead to more attitude change than messages with familiar, valid and relevant arguments.

At the time these studies were carried out, ethical approval was not customary; however, all procedures would have been approved by currently accepted standards.

\section{STUDY 1: ELICITATION OF ARGUMENTS}

To determine the influence of new and familiar arguments, we first needed to manipulate the level of novelty versus familiarity of arguments in both directions of the scale. An initial study was therefore conducted in order to select these arguments.

\section{METHOD}

The attitude topic chosen for use in this study is not from the area of health promotion. There is, however, no reason to assume that the process would be any different for topics or issues which are related to health promotion. In line with our wish to use a relevant but rarely discussed topic, we decided on "Punishments and rewards in education". The participants in our studies were all high school students or first year university students, meaning that this topic was highly relevant to them. At the same time, we did not consider this to be a widely discussed topic within educational settings. The topic was therefore deemed suitable in terms of identifying new arguments.

Potential arguments were collected among 27 high school students, 16 first year Psychology students, 20 teachers and 14 educational scientists and educational psychologists. They were asked to provide as many arguments as possible either in favor of or against the following statement: "In education, punishments should not be used; only good behavior should be rewarded. This will improve learning achievements". We expected that some of the arguments of scientists would be new to the non-experts.

\section{RESULTS}

In total, 230 arguments were collected. The researchers divided these arguments into two groups, based on consensus discussions: in favor of, or against, the chosen statement. For later use in the second study, the arguments were then sorted into 15 categories in each direction. This process combined arguments with similar content into single categories (nine arguments were uninterpretable). For each of the 30 categories, one argument was then selected to represent that category, resulting in 30 arguments (15 in favor of the statement and 15 against).

\section{STUDY 2: SELECTING NEW VERSUS FAMILIAR ARGUMENTS}

A second study was conducted in order to assess the arguments generated in study 1 in terms of validity, relevance, novelty, and direction (in favor of or against).

\section{METHOD}

The 30 arguments were evaluated by 76 high school students (grades 4 and 5). Students read the arguments and judged them on four characteristics using 5-point scales, ranging from "Highly" to "Not at all":

New versus familiar: "We would like to know, in relation to the arguments listed below, whether you are already familiar with these arguments or not. An argument is highly new for you if you don't know it, have never heard about it and have never thought about it. An argument is highly familiar to you if you do know it, have heard about it often, and have thought about it often".

Direction (in favor or against): "We would like to know if you think the arguments listed below are in favor of or against the statement provided. An argument can be seen as highly in favor of the statement if it expresses an opinion in line with (in the same directions as) the statement. An argument can be seen as highly against the statement if it expresses an opinion in opposition to (in the opposite direction of) the statement. Note that this is not about your own opinion but only about the direction of the argument".

Valid or invalid: "We would like to know if you think, given the statement, that the arguments listed below are valid or invalid. An argument can be described as highly valid if you think that the main contention of the argument is completely true. An argument can be described as highly invalid if you think that the main contention of the argument is completely untrue”.

Relevant or irrelevant: "We would like to know if you think, given the statement provided, that the arguments listed below are relevant or irrelevant. An argument is highly relevant if the main contention of the argument is clearly related to the topic of the statement. An argument is highly irrelevant if the main contention of the argument has nothing to do with the topic of the statement".

In this way, evaluations of all 30 arguments were garnered. The judges (participants) were also asked to record their own opinion on the statement about punishment or rewards, using a 5-point Agree-Disagree scale. Based on these responses, two groups were formed: pro-rewardjudges and anti-reward judges. It was necessary to make this distinction because in the third and final study, we 
needed to be able to provide (under the guise of a cover story) counter arguments to participants who disagreed with the direction of these arguments.

\section{RESULTS}

The means for novelty, validity and relevance of proreward arguments were calculated for anti-reward participants, and the means for novelty, validity and relevance of anti-reward arguments were calculated for pro-reward participants. The means for direction were as expected. They confirmed the direction that the researchers had initially assigned the arguments in Study 1. In both groups, four (relatively) new arguments and just one familiar argument (to reduce the possibility of introducing novel information in the familiar condition) with the highest possible validity and relevance were selected. The evaluations are presented in Table 1.

The four familiar arguments that were later used in the third and final study are variations of the same argument. This argument is also included in the description of the attitude-issue that the participants in Study 3 read before recording their own opinion. The final formulation of the arguments is provided in Table 2. The arguments are presented in the same order as in Table 1. The familiar argument in Table 1 is therefore the first familiar argument in Table 2.

\begin{tabular}{llllll}
\hline PRO-REWARD ARGUMENTS & DIRECTION & NOVELTY & VALIDITY & RELEVANCE \\
\hline New arguments & 1 & 3.4 & 3.7 & 2.7 & 3.2 \\
\cline { 2 - 6 } & 2 & 3.5 & 3.1 & 3.5 & 3.4 \\
\cline { 2 - 6 } & 3 & 3.3 & 3.4 & 3.3 & 3.3 \\
\cline { 2 - 6 } & 4 & 3.3 & 3.7 & 2.7 & 2.6 \\
\hline Familiar argument & 1 & 3.6 & 1.8 & 3.6 & 3.8 \\
\hline ANTI-REWARD ARGUMENTS & DIRECTION & NOVELTY & VALIDITY & RELEVANCE \\
\hline New arguments & 1 & 2.5 & 3.8 & 3.1 & 3.1 \\
\cline { 2 - 6 } & 2 & 3.0 & 3.6 & 3.5 & 2.6 \\
\cline { 2 - 6 } & 3 & 2.0 & 3.4 & 2.5 & 3.3 \\
\cline { 2 - 6 } & 4 & 2.4 & 3.3 & 2.9 & 2.7 \\
\hline Familiar argument & 1 & 1.9 & 2.6 & 2.4 & 2.4 \\
\hline
\end{tabular}

Table $1^{*}$ Evaluation of arguments; 1 = Low, 5 = High; for direction 1 = Against, 5 = In favor.

* SDs were unfortunately not reported in the dissertation.

\begin{tabular}{|c|c|c|}
\hline \multicolumn{3}{|c|}{ ARGUMENTS IN FAVOR OF USING REWARDS } \\
\hline $\begin{array}{l}\text { New } \\
3.7\end{array}$ & 1 & $\begin{array}{l}\text { Using rewards is a more efficient and easy-to-tailor means of maximizing (or improving) learning achievements. For } \\
\text { example, a reward, in contrast to a punishment, makes it clear exactly what the desired behavior is. }\end{array}$ \\
\hline 3.1 & 2 & $\begin{array}{l}\text { The use of rewards emphasizes what the student is able to do; contrary to the use of punishment. The use of rewards } \\
\text { therefore leads to students developing a more positive self-image. }\end{array}$ \\
\hline 3.4 & 3 & $\begin{array}{l}\text { As a result of using rewards, less talented and less competent students will be better protected, because they will receive } \\
\text { positive attention. }\end{array}$ \\
\hline 3.7 & 4 & $\begin{array}{l}\text { In particular, rewards lessen competitiveness among students, which in turn improves the interpersonal relationships } \\
\text { among students. }\end{array}$ \\
\hline \multirow{4}{*}{$\begin{array}{l}\text { Familiar } \\
1.8\end{array}$} & 1 & One consequence of using rewards is that the individual relationship between the student and the teacher will improve. \\
\hline & 2 & Students will work harder for a teacher with whom they have a better relationship. \\
\hline & 3 & As a result of using rewards, the atmosphere in the classroom will improve. \\
\hline & 4 & Teachers who use punishment will never have a positive relationship with their students. \\
\hline \multicolumn{3}{|c|}{ ARGUMENTS AGAINST USING REWARDS } \\
\hline $\begin{array}{l}\text { New } \\
3.8\end{array}$ & 1 & $\begin{array}{l}\text { Punishments may be very effective if linked to undesirable behavior. To only use rewards requires the teacher to be } \\
\text { very skillful. }\end{array}$ \\
\hline 3.6 & 2 & The use of rewards is only reinforcing when there is also a counteraction; ignoring bad behavior is in fact a form of punishment. \\
\hline 3.4 & 3 & Repeatedly using rewards will decrease their value; punishment is a necessary counteraction. \\
\hline 3.3 & 4 & $\begin{array}{l}\text { Avoiding the use of punishment altogether creates a huge difference between school and society, including home life. } \\
\text { This may lead to adaptation problems. }\end{array}$ \\
\hline \multirow{4}{*}{$\begin{array}{l}\text { Familiar } \\
2.6\end{array}$} & 1 & Bad behavior should be punished, otherwise students will keep repeating the bad behavior. \\
\hline & 2 & The use of punishments is the only way to counter bad behavior. \\
\hline & 3 & As a consequence of not using punishments, bad behavior is in fact promoted. \\
\hline & 4 & Sometimes it is really necessary to use punishments. \\
\hline
\end{tabular}

Table 2 The arguments (with novelty scores: 1-5). 


\section{STUDY 3: EFFECTS OF NEW VERSUS FAMILIAR ARGUMENTS ON ATTITUDES}

To examine the effects of new arguments versus familiar arguments on attitudes, the third study exposed participants to two conditions, one with (relatively) new arguments and one with (relatively) familiar arguments.

\section{METHOD}

\section{Design}

In this study, we tried to influence participants using the arguments generated in the earlier studies. We used the classic Crutchfield (1953) situation: participants arrived in groups, were at random placed in separate booths and received fabricated information about the responses of the other participants, i.e. they were told that they would be reading arguments formulated by their fellow participants. We in fact manipulated whether the (previously generated) arguments presented were new or familiar. In the high novelty condition, participants were exposed to four valid, relevant and new arguments. In the low novelty condition, participants were exposed to four valid, relevant and familiar arguments. In this way, the influence of arguments was manipulated without the participants being able to tell whether different numbers of individuals supported each of these arguments. The arguments needed for this manipulation were selected (based on their mean scores) from those generated in studies 1 and 2. We expected that attitude change would be greater in the direction of the arguments in the high novelty condition (comprising new arguments) compared to the low novelty condition (comprising familiar arguments).

\section{Procedure}

Participants were randomly divided over two conditions and, based on their initial position regarding the two statements (seeAttitudetopic), exposed to four arguments counter to their own position: four new counterarguments in one condition, four familiar counterarguments in the other condition. Participants arrived in groups of eight. Each participant was placed in one cubicle and received instructions through a headphone. Participants were seated in front of a screen on which the statements could be shown, and a keyboard on which they could provide responses to indicate their opinions. In the first part of the experiment, participants were shown 20 topics. Each topic was introduced with a short text, and the participants were asked to indicate what their opinion was on a 100-point scale with extremely contradictory opinions at each end. The target topic of this study rewards or punishments in education - was presented as the sixth topic. Having given their opinions on all 20 topics, and after a short break, the target topic - rewards or punishments in education - was shown again. Our assumption was that participants would not remember the exact score they had previously given for this topic. The participants then received four arguments with the instruction: "These arguments are related to this topic and were mentioned by earlier participants". Dependent on the condition, participants received four new or four familiar arguments. Participants had two minutes to think about the topic statement and the provided arguments, and then gave their final opinion.

\section{Participants}

Participants were 43 students of the School of Law at the University of Groningen (data about age and gender are not available; also, it was not customary to perform power analyses at the time this data was collected). Attitude topic. Participants gave their opinion on 20 topics about society in general. The sixth topic was the target topic. The description was as follows:

\section{"The next topic is: Rewards and punishments in education. In education, students are repeatedly told how they have performed. Good behavior and good achievements are rewarded. Bad behavior and bad achievements are punished. Some are of the opinion that, in education, one should only use rewards and stop using punishments, resulting in a much better contact between teacher and student. As a result, students' achievements will improve. Another opinion is that punishment of bad behavior is particularly necessary because bad behavior will be encouraged when it is not punished. Punishment will therefore result in better achievements."}

The two extreme statements in relation to this topic are:

$0=$ In education, one should not use punishments, but only reward good behavior. This will lead to better achievements.

$99=$ In education, rewards should be rare, while bad behavior should be punished. This will lead to better achievements.

\section{Measures}

Attitude change was measured by comparing the responses provided on the 100-point scale before and after reading the four arguments provided. When the second opinion score had moved towards the middle of the scale, i.e. in the direction of the counterarguments, this difference was scored as a positive change. When it moved in the opposite direction, this was scored as a negative change.

\section{RESULTS}

\section{Checks}

From information gleaned from the post-experiment meetings with the participants, it was concluded that none of them distrusted the source of the given arguments. 
Moreover, the participants' opinions on the first measurement did not differ between the two conditions (>.6).

\section{Attitude change}

As hypothesized, we observed more attitude change in the condition with high novelty (new arguments) than in the condition with low novelty (familiar arguments): $\mathrm{M}_{\text {new }}=10.59(\mathrm{~N}=22)$ against $\mathrm{M}_{\text {fam }}=0.62(\mathrm{~N}=21)$; $F(1,41)=9.34 ; p=.004 ; d=9.34, d f=41,(0.345 ; 1.620)$.

\section{GENERAL DISCUSSION}

Messages with new, valid and relevant arguments led to more attitude change than messages with familiar, valid and relevant arguments. And perhaps obviously, there was no attitude change in the condition with familiar arguments. These data support the notion that certain parameters need to be met in order for arguments to be effective: "For central processing of arguments they need to be new to the message receiver" (Burnstein \& Vinokur, 1977; Bartholomew Eldredge et al., 2016; Kok et al., 2016). Just using arguments, even when they are valid and relevant, will not automatically lead to attitude change; attitude change is more likely to occur only when those arguments are also new to the receiver. That may be relatively evident, but as far as we know, there has been no other empirical evidence for this phenomenon since Burnstein \& Vinokur, 1977 and Vinokur \& Burnstein, 1978). Broecks et al., 2016 studied novelty of arguments but not novelty combined with relevance and validity, and found no effect of that type of novelty.

Identifying new arguments that are also valid and relevant is a time-consuming and difficult process. Given the small differences between high and low novelty, for some of the participants even the "highly novel" arguments may not have been new, which would have weakened the effect. However, if so, this will also be the case in real life. In hindsight, the texts of the new arguments turned out to be somewhat longer than those of the familiar arguments. However, if argument length was indeed influential, the effect of that difference could have been in favor of the hypothesis: peripheral processing might lead to more effect of longer arguments, or just as feasibly against the hypothesis: central processing might lead to less effect of longer arguments. Moreover, the statement about rewards and punishments was not unambiguous; however, the selection of stimulus arguments was based on participants' own judgments.

The participants in study 1 were high school students and those in study 2 were university students, which may have influenced the experience of novelty of the arguments. However, if that were a relevant factor, it would have decreased the effect.

As mentioned earlier, the attitude topic chosen is not related to the field of health promotion, due to the difficulties of generating new arguments in relation to a topic that is highly relevant to the participants. There is, however, no reason to assume that this process would be different for health promotion topics as long as the arguments used are novel, relevant, valid and in the right direction for the target population. The power of this study is low and replication studies would be advisable as we are not aware of any comparable experimental studies.

In real life, novelty of arguments is only part of information processing. For example, Prahl et al. (2017) studied argument novelty in a study on polarization during group discussions and found no effect of novelty of arguments. They suggest that social validation of shared information may be more important than novelty.

Nevertheless, the outcomes are exactly as hypothesized: Messages with new, valid and relevant arguments lead to more attitude change than messages with familiar, valid and relevant arguments. It may be beneficial for health promoters to use (carefully crafted) new persuasive arguments at the individual level to encourage people to adopt healthful behaviors, as well as new persuasive arguments to influence agents at higher ecological levels. For example, viewing a television broadcast on the impact of environmental tobacco smoke on children's health - and the benefits of protecting children from environmental smoke - may influence a mother to declare her home smoke free, as she had not been aware of those negative effects. Seeing other legislators receive media attention for promoting a healthy policy may lead legislators to vote for health legislation, as they may not have realized that the media would be interested in such topics. In either of these cases, the receivers must both expect new positive (health) outcomes and value those outcomes in order for persuasion to be effective (Bartholomew Eldredge et al., 2016).

All of the arguments used in this study were sufficiently high in validity and relevance, to ensure that we only manipulated whether the argument was new or familiar. In a broader context, novelty may also be interpreted as giving new information that counters existing beliefs. For example, in a study among mail delivery drivers, Siero et al. (1989) found that delivery drivers who had a low intention to adopt a fuel saving driving style differed from delivery drivers with a high intention; they did agree that a fuel saving driving style might save energy, but they also thought that a fuel saving driving style would make the engine 'lazy' and would make them fall behind schedule. Both these beliefs are factually wrong. The drivers with low intentions were unaware what their colleagues thought about a fuel saving driving style. As part of the intervention that Siero et al. developed, both misunderstandings were corrected, and a positive perceived norm was introduced. Their intervention resulted in a significant reduction in fuel use by the group of delivery drivers that received the intervention (Siero et al., 1989). 
Tailoring interventions to a careful inventory of existing beliefs, as illustrated above, is a crucial element in the Reasoned Action Approach/Theory of Planned Behavior (Fishbein \& Ajzen, 2010. This so-called elicitation procedure is a necessary precondition for the development of persuasive communication or other interventions that can be used to change attitudes, perceived norms and perceived behavioral control; a precondition that is too often ignored (Ajzen, 2015):

\begin{abstract}
"An intervention designed to create more favorable intentions requires pilot work that involves (i) eliciting readily accessible behavioral, normative and control beliefs in a representative sample of the target population, (ii) selecting specific existing accessible beliefs or, often better, novel beliefs not emitted in the elicitation stage to target in the intervention, (iii) designing an intervention (e.g., persuasive message, group discussion, modelling, etc.) that attacks the selected beliefs, (iv) making sure that the intervention produces large changes in the targeted beliefs and that it does not have countervailing impact effects on unmentioned beliefs and...” (Ajzen, 2015, p. 136).
\end{abstract}

To summarize, an intervention designed to change attitudes, perceived norms, perceived behavioral control, intentions or behaviors should focus on messages containing new arguments or novel beliefs. Moreover, the content of these messages should be based on the results of pilot studies that can help to identify new arguments or novel beliefs in relation to that particular target population (the receivers).

In conclusion, it has become clear in recent years that certain parameters for effectiveness need to be taken into account in relation to all behavior change methods (Bartholomew Eldredge et al., 2016; Kok et al., 2016). In this article, we have demonstrated the importance of one particular parameter - novelty - for the behavior change method 'Arguments', part of a broader behavior change method called 'Persuasive communication'. These studies have demonstrated that, to ensure the central processing of arguments, messages need to be new to the receiver. Experimental studies identifying parameters for effectiveness in relation to various behavior change methods are, unfortunately, scarce. There is, however, a great need for these kinds of studies, in order to provide evidence for the conditions under which interventions may be more or less successful (Peters et al., 2015).

\section{COMPETING INTERESTS}

The author has no competing interests to declare.

\section{AUTHOR AFFILIATION}

Gerjo Kok (D) orcid.org/0000-0002-3501-4096

Maastricht University, NL

\section{REFERENCES}

Ajzen, I. (2015). The theory of planned behaviour is alive and well, and not ready to retire: a commentary on Sniehotta, Presseau, and Araújo-Soares. Health Psychology Review, 9(2), 131-137. DOI: https://doi.org/10.1080/17437199.201 4.883474

Bartholomew Eldredge, L. K., Markham, C. M., Ruiter, R. A. C., Fernández, M. E., Kok, G., \& Parcel, G. S. (2016). Planning health promotion programs: An Intervention Mapping approach, 4th edition. San Francisco, CA: Jossey-Bass. ISBN-13: 978-1119035497.

Broecks, K. P., van Egmond, S., van Rijnsoever, F. J., Verlindevan den Berg, M., \& Hekkert, M. P. (2016). Persuasiveness, importance and novelty of arguments about Carbon Capture and Storage. Environmental Science \& Policy, 59, 58-66. DOI: https://doi.org/10.1016/j.envsci.2016.02.004

Burnstein, E., \& Vinokur, A. (1977). Persuasive argumentation and social comparison as determinants of attitude polarization. Journal of Experimental Social Psychology, 13(4), 315-332. DOI: https://doi.org/10.1016/00221031(77)90002-6

De Bruin, M., Crutzen, R., \& Peters, G.-J. Y. (2015). Everything should be as simple as possible, but this will still be complex: A reply to various commentaries on IPEBA. Health Psychology Review, 9(1), 38-41. DOI: https://doi.org/10.108 0/17437199.2014.981833

Crutchfield, R. S. (1953). Correlates of individual behavior in a controlled group situation. American Psychologist, 8(338), 191-198.

Crutzen, R., \& Peters, G. J. Y. (2017). Evolutionary learning processes as the foundation for behaviour change. Health Psychology Review, online. DOI: https://doi.org/10.1080/174 37199.2017.1362569

Fishbein, M., \& Ajzen, I. (2010). Predicting and changing behavior: The reasoned action approach. New York, NY: Psychology Press. DOI: https://doi. org/10.4324/9780203838020

Kok, G. (1983). Attitudeverandering binnen groepen; standpunten en argumenten (Attitude change within groups; positions and arguments). PhD Dissertation, University of Groningen.

Kok, G., Gottlieb, N. H., Peters, G.-J. Y., Mullen, P. D., Parcel, G. S., Ruiter, R. A. C., Fernández, M. E., Markham, C., \& Bartholomew, L. K. (2016). A Taxonomy of behavior change methods; an Intervention Mapping approach. Health Psychology Review, 10(3), 297-312. DOI: https://doi. org/10.1080/17437199.2015.1077155 
Kok, G. J., Wilke, H., van Knippenberg, A., \& Meertens, R. W. (1986). Attitudeverandering en sociale vergelijking (Attitude change and social comparison). In A. van Knippenberg, M. Poppe, J. Extra, G. J. Kok \& E. Seijdel (Red.), Fundamentele sociale psychologie, deel 1 (pp. 61-74). (Fundamental Social Psychology, 1). Tilburg University Press.

McGuire, W. J. (2012). McGuire's classic input-output framework for constructing persuasive messages. In R. E. Rice \& C. K. Atkin (Eds.), Public communication campaigns (4th ed., pp. 133-146). Thousand Oaks, CA: Sage. DOI: https://doi.org/10.4135/9781544308449.n9

Peters, G.-J. Y., de Bruin, M., \& Crutzen, R. (2015). Everything should be as simple as possible, but no simpler: Towards a protocol for accumulating evidence regarding the active content of health behavior change interventions. Health Psychology Review, 9(1), 1-14. DOI: https://doi.org/10.108 0/17437199.2013.848409

Peters, G.-J. Y., \& Kok, G. (2016). All models are wrong, but some are useful: a comment on Ogden (2016) on how to celebrate variability of persons, variability of theories, and systematic behaviour change application and research. Health Psychology Review, 10(3), 265-268. DOI: https://doi. org/10.1080/17437199.2016.1190658

Petty, R. E., Barden, J., \& Wheeler, S. C. (2009). The Elaboration Likelihood model of Persuasion: Developing health promotions for sustained behavioral change. In R. J. DiClemente, R. A. Crosby \& M. Kegler (Eds.), Emerging theories in health promotion practice and research (2nd ed., pp. 185-214). San Francisco, CA: Jossey-Bass.

Petty, R. E., Briñol, P., Fabrigar, L., \& Wegener, D. T. (2019). Attitude Structure and Change. In E. J. Finkel \& R. F.
Baumeister (Eds.), Advanced social psychology: The state of the science (pp. 217-259). Oxford: Oxford University Press.

Petty, R. E., \& Wegener, D. T. (1998). Attitude change Multiple roles for persuasive variables. In D. T. Gilbert, S. T. Fiske \& G. Lindzey (Eds.), The handbook of social psychology (4th ed., pp. 323-390). Boston: McGraw-Hill.

Prahl, A., Van Swol, L. M., \& Kolb, M. R. (2017). Silent minority: argument, information sharing, and polarization of minority opinion through a structuration theory lens. Journal of Applied Communication Research, 45(4), 381-396. DOI: https://doi.org/10.1080/00909882.2017.1355557

Siero, S., Boon, M. E., Kok, G., \& Siero, F. W. (1989). Modification of driving behavior in a large transport organization: a field experiment. Journal of Applied Psychology, 74, 417-423. DOI: https://doi. org/10.1037/0021-9010.74.3.417

Vinokur, A., \& Burnstein, E. (1978). Novel argumentation and attitude change: The case of polarization following group discussion. European Journal of Social Psychology, 8(3), 335-348. DOI: https://doi.org/10.1002/ejsp.2420080306

\section{PEER REVIEW COMMENTS}

Health Psychology Bulletin has blind peer review, which is unblinded upon article acceptance. The editorial history of this article can be downloaded here:

- PR File 1. Peer Review History. DOI: https://doi. org/10.5334/hpb.13.pr1

TO CITE THIS ARTICLE:

Kok, G. (2021). Novelty as a Parameter for Using Arguments in Persuasive Communication. Health Psychology Bulletin, 5(1), pp. 12-19. DOI: https://doi.org/10.5334/hpb.13

Submitted: 11 January 2018 Accepted: 21 January 2021 Published: 03 February 2021

\section{COPYRIGHT:}

(c) 2021 The Author(s). This is an open-access article distributed under the terms of the Creative Commons Attribution 4.0 International License (CC-BY 4.0), which permits unrestricted use, distribution, and reproduction in any medium, provided the original author and source are credited. See http://creativecommons.org/licenses/by/4.0/.

Health Psychology Bulletin is a peer-reviewed open access journal published by Ubiquity Press.

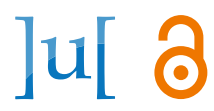

